\title{
EXPLOTACIÓN FORESTAL E INDUSTRIA RESINERA EN ESPAÑA: 1900-1936
}

\author{
POR
}

\author{
RAFAEL URIARTE AYO
}

El aprovechamiento industrial del bosque ha sido uno de los elementos más relevantes en la economía rural de una buena parte del territorio español. Avanzar en el conocimiento de las actividades vinculadas a la explotación forestal, cualquiera que sea el momento histórico analizado, requiere, por lo general, un esfuerzo centrado en espacios y aprovechamientos muy definidos. Un país de amplia y diversificada geografía no tiene una sola historia forestal. Cada territorio, en función de su propia evolución histórica y de las específicas condiciones medioambientales (suelo, clima, relieve, etc.), presenta rasgos diferenciales que es necesario reconstruir de manera individualizada ${ }^{1}$.

Actualmente relegada a una ocupación meramente residual ${ }^{2}$, la extracción de resina ha sido, sin embargo, una de las industrias forestales más extendidas en los pinares castellanos y de otras regiones de la España rural. Aunque se trata de una actividad integrada finalmente en el complejo y heterogéneo sector químico, nos centraremos en analizar el núcleo estrictamente forestal de donde arranca la industria ${ }^{3}$.

\footnotetext{
${ }^{1}$ Estudio incluido en el proyecto de investigación sobre «La modernización de la industria rural: los sectores agroalimentario y forestal» (UPV 012.321-HA038/95).

${ }^{2}$ Tras un largo período de declive, la industria resinera española, al igual que ha ocurrido con otros países productores (Francia, EE.UU., etc) ha sido inevitablemente desplazada por el cambio técnico y los productos procedentes de países con extensos recursos forestales y mano de obra barata (China, Rusia o Brasil, entre otros).

${ }^{3}$ Un planteamiento más global puede verse en R. Uriarte Ayo (1995a y b).

Estudios Geográficos

Tomo LXI, 2000, n. ${ }^{\circ} 241$, octubre-diciembre 


\section{La formación de un espacio forestal}

La resinación en España ha afectado a tres especies fundamentales de coníferas autóctonas: el pino negral (Pinus pinaster), el pino laricio o salgareño (Pinus nigra) y el pino carrasco (Pinus halepensis) ${ }^{4}$. La más difundida de las citadas especies, de acuerdo con datos referidos a 1929, es el pino negral, que se encuentra en 37 provincias españolas, le sigue el pino laricio con presencia en 25 provincias y, finalmente, el pino carrasco que existe en 21 provincias ${ }^{5}$. Para igual fecha, en cifras globales, incluyendo montes públicos y privados, la hegemonía del pino negral, en cuanto al número de pinos resinados, es evidente, representando prácticamente el $90 \%$ del total.

\section{CUADRo I}

DISTRIBUCIÓN POR ESPECIES DE LOS ÁRBOLES RESINADOS (1929)

\begin{tabular}{lccc}
\hline & Pino negral & Pino carrasco & Pino laricio \\
\hline TотAL & 16.152 .550 & 1.126 .783 & 750.000 \\
Porcentaje & 89,7 & 6,2 & 4,1 \\
\hline
\end{tabular}

Fuente: M. Tomeo (1939), p. 28.

Muy utilizado en las repoblaciones forestales contemporáneas llevadas a cabo en España, especialmente en Galicia, el pino negral es apreciado por la calidad de su madera, la rapidez de crecimiento, pero, sobre todo, por su elevado rendimiento resinero. Existen dos subespecies diferentes, una mediterránea y otra atlántica. La mediterránea, claramente orientada a la producción resinera, se encuentra en ambas Castillas, principalmente en los suelos de textura suelta, arenosa, de Segovia y Valladolid, en las sierras de Guadarrama y Gredos, en la serranía de Cuenca, en las provincias de Soria y Guadalajara, y en la Andalucía Alta (Jaén, Granada, Málaga) ${ }^{6}$. La subespecie atlántica, de crecimiento

${ }^{4}$ Durante períodos muy cortos también fue resinado la variedad de pino canario.

${ }^{5}$ M. Tomeo (1939), pp. 25-26.

${ }_{6}$ A. Cid Ruiz-Zorrilla (1941), p. 24. 
más lento y más apreciada por su madera, se extiende particularmente en Galicia y, en menor medida, en Asturias, como prolongación de su área natural original, situada en las dunas costeras del norte de Portugal 7 . El pino laricio, especie de transición entre los climas mediterráneo y atlántico, encuentra sus más extensos bosques en la serranía de Cuenca y en las sierras de Cazorla y de Segura. Aunque en ausencia del pino negral y en los momentos de más intensa demanda, ha sido resinado, su explotación ha estado preferentemente orientada a la obtención de madera $^{8}$. El pino carrasco, caracterizado por su resistencia a las elevadas temperaturas y a las prolongadas sequías, se encuentra principalmente en terrenos áridos, arenosos o pedregosos, próximos al Mediterráneo y cabeceras del Tajo y Guadiana, habiendo sido objeto de extensas repoblaciones.

Se trata, como se ha indicado, de especies todas ellas autóctonas, aunque sus manifestaciones estén, con frecuencia, profundamente transformadas por la acción del hombre. Las numerosas referencias existentes sobre la presencia del pinar en la documentación medieval ${ }^{9}$ descartan, desde luego, cualquier versión que vincule su difusión a posibles repoblaciones realizadas en fechas más recientes ${ }^{10}$, lo cual, obviamente, no descarta la permanente intervención humana , en un sentido u otro. En cualquier caso, la acción del hombre se vio intensificada como consecuencia del creciente intervencionismo de las administraciones contemporáneas. A partir de la segunda mitad del siglo XIX y, en especial, tras la promulgación de la ley de repoblación de 1877 y la regulación de los planes de ordenación según Real decreto de 1890, la «modernización» del monte avanzó con rapide ${ }^{11}$. De acuerdo con el principio dasonómico de «ordenar transformando», los montes bajo la tutela del estado fueron adquiriendo las características que mejor se adaptaban a las

${ }^{7}$ C. Ferreras, M. ${ }^{a}$ E. Arozena (1995), p. 182.

${ }^{8}$ En la Memoria de LURE correspondiente al año 1899 podemos leer al respecto que, «el instinto imitativo conduce a algunos ilusos al aprovechamiento resinoso en el pino Laricio, pero su escasa producción apenas si llega a un litro resinado a muerte, eleva el coste de mano de obra, que hace del todo punto imposible la concurrencia con la producción del pino Ródeno. No es aventurado augurar el fracaso más completo en todo negocio industrial que en ésto se funde» (Memoria LURE 1899, p. 7)

${ }^{9}$ L. Gil (1991).

10 V. Clement (1999) ha criticado recientemente «el mito de las repoblaciones masivas de los siglos XV-XVI», planteado por H. Hopfner (1954).

${ }^{11}$ Una visión general de la política forestal contemporánea, puede verse en $\mathrm{H}$. Grome (1985 y 1988), J. Sanz Fernánez (1985) y J.I . Jiménez Blanco (1991). 
exigencias del mercado. En este nuevo contexto, la sustitución de las frondosas por especies de crecimiento rápido, especialmente coníferas, fue una de las medidas más frecuentes y extendidas ${ }^{12}$. En concreto, allí donde la industria resinera tuvo mayor implantación, el pino negral fue intensamente utilizado en las repoblaciones promovidas por el estado y por particulares, desplazando a otras especies, ocupando baldíos, arenales, terrenos utilizados para pastos de mediocre calidad, etc. No obstante, aunque resulte difícil precisar lo ocurrido en cada uno de los espacios, la expansión de las coníferas no ha implicado necesariamente la sustitución y regresión de frondosas u otros bosques climácicos.

En lugares como la Tierra de Pinares de Segovia y en otras zonas de condiciones muy semejantes existentes en Avila, Valladolid, etc., es probable que el Pinus pinaster constituya la especie climácica original, perfectamente adaptada a unos terrenos pobres y arenosos. En estos montes de llanura, el arbolado era el único medio para fijar las dunas e impedir que en su progresión llegasen a invadir las tierras de labor. De hecho cuando se practicaron talas abusivas con objeto de ampliar los cultivos, no se tardó en comprobar la amenaza que ello podía llegar a suponer para los pueblos y comunidades limítrofes ${ }^{13}$.

La intervención humana, en cualquier caso, ha favorecido la difusión del pinaster, especie natural en determinadas áreas de clima mediterráneo-frío del interior, permitiendo su extensión hacia otras zonas peninsulares, para, de este modo, alcanzar una amplísima presencia en la geografía española ${ }^{14}$. $L U R E$, la empresa que lideró la industria resinera española, nos proporciona un excelente ejemplo de los medios

12 J. Sanz Fernández (1985), p. 199 y (1986), p. 167.

13 «En algunos sitios, como en el monte «Común grande de los Pegueros» (Segovia) y en Portillo (Valladolid) la duna llega a alcanzar proporciones alarmantes. En la primera y frente al pueblo de Hontalbilla se da el caso curioso de que habiendo sido este pueblo, entre otros, causa de la tala espantosa practicada en aquel monte y por hallarse situado al NE. Del mismo, han visto asustados sus vecinos que a medida que alejaban el arbolado con sus desmedidas cortas, de los cultivos que mediaban entre el pueblo y aquel, el monte vomitaba con los vientos del SO. Que son los dominantes, las estériles arenas sobre sus viñas y sus campos, y sólo así han podido ver palpablemente y muestran a quien los visite aquel ejemplo clarísimo de la influencia dirtecta y de una transcendencia incalculable que para esta región tiene allí el monte» (J. Iturralde, O. Elorrieta, 1914, p. 36).

${ }_{14}$ G. Calonge Cano (1987), p. 168. En las llanuras de Castilla la Vieja, el pinaster se entremezcla frecuentemente con el pino piñonero, de manera que ha sido el mercado, en función de la evolución de los precios de la resina y el piñón, lo que ha determinado la difusión de una u otra especie (A. Nicolas, J. M. Gandullo, 1967, p. 20).

$$
-658-
$$


utilizados por la iniciativa privada en la repoblación ${ }^{15}$. Fue en los años veinte, en pleno proceso expansivo de la empresa y del sector en su conjunto, cuando la entidad realizó el esfuerzo más notable en este terreno ${ }^{16}$. Con un extensísimo patrimonio forestal, cercano a las 70.000 Has., los métodos de repoblación fueron necesariamente variados, «empleándose en ciertos sitios la labor de arado y sembrado a boleo; en otros, mezclando la semilla con cereal, y en fin, dada la enorme extensión de nuestras propiedades, podemos decir que todos los procedimientos conocidos han sido empleados por haber precedido a esta operación un serio estudio» ${ }^{17}$. Cuando se trataba de superficies de matorral, se aprovechaba su arranque para realizar repoblaciones con reducido coste, «obligando al que arranca la jara a depositar piñones en el suelo removido y $\sin$ más labor se han obtenido satisfactorios resultados» ${ }^{18}$. En ocasiones, las repoblaciones implicaban sustitución de especies, generalmente reemplazando el pino piñonero por el pinaster, para lo cual se buscaban los procedimientos menos gravosos para la empresa, «haciendo la corta y con objeto de lograr la repoblación artificial, cosa muy difícil en la meseta central de Castilla, se han dado los terrenos en renta a los vecinos de los pueblos limítrofes para que ellos los roturan y cultiven durante tres años, con el compromiso de arrojar la última simiente mezclada con piñón, que encontrando el terreno muy preparado por las labores de tres años anteriores, y sirviéndole de cierto abrigo la misma paja del cereal que con él se sembró, asegurar el éxito de la transformación, percibiendo aún la RESINERA alguna remuneración» ${ }^{19}$. Tras la repoblación, la limpieza y el cuidado de las plantaciones exigía un importante esfuerzo, llevándose a cabo «a jornal a destajo, en otros regalando la mata al que la arranque y en otros, en fin, por su proximidad a centros consumidores, vendiéndola ésta o carboneándola» ${ }^{20}$.

La política de ordenaciones y repoblación, seguida con distinto criterio e intensidad en función de las cambiantes circunstancias históricas,

${ }^{15}$ Sobre el desarrollo de $L U R E$, ver R. Uriarte Ayo (1996).

16 «Siendo abundantes los rasos de todos los montes, unos que datan de tiempo inmemorial, sin dar más utilidad que algún pasto, y otros producidos por incendios, se ha procedido a su repoblación, y este año se han efectuado con éxito notorio importantes siembras y plantaciones en casi todos los montes de la Sociedad» (Memoria LURE 1924-1925, p. 6).

${ }_{17}$ Memoria LURE 1924-1925, pp. 6-7.

18 Ibídem.

19 Ibídem.

${ }^{20}$ Ibídem. 
ha propiciado, a largo plazo, la formación de masas forestales homogéneas, monoespecíficas y regulares. De acuerdo con los principios dasocráticos establecidos en cada caso, se trataba, en última instancia, de favorecer la explotación industrial del bosque. Dada la importancia del monte público en el aprovechamiento resinero, la actuación de la administración en este terreno ha sido, sin duda, decisiva. Ello, no obstante, no debe hacernos olvidar que la intervención de los organismos públicos no se producía de forma aislada. Aunque nuestra información puede ser más escasa, los intereses privados de empresas transformadoras y propietarios forestales estuvieron siempre presentes. De hecho, sería erróneo establecer barreras entre lo privado y lo público cuando en realidad quienes promovieron los primeros y más importantes planes de ordenación fueron precisamente los propios industriales ${ }^{21}$. En este sentido, los ingenieros forestales, muchos de ellos estrechamente vinculados a la empresa privada, al tratar de adecuar la producción del monte público a las demandas del mercado, no hacían otra cosa que atender las necesidades de las empresas transformadoras. La intervención, en todo caso, de administraciones públicas, empresas y particulares, a través de la repoblación, la explotación «ordenada»o el aprovechamiento depredador, ha supuesto la práctica desaparición de lo que podríamos calificar como «bosques naturales» y su sustitución por monocultivos forestales, sometidos a explotaciones más o menos intensivas y regularizadas.

La influencia alemana en este terreno fue, como es sabido, fundamental. A través de ingenieros como A. Pascual, C. Bordiú y de quienes integraron las primeras promociones de la Escuela Especial de Ingenieros de Montes de Villaviciosa de Odón, se difundieron las ideas desarrolladas en la obra de los forestalistas alemanes de la escuela de Tharandt, especialmente H. Cotta y R. Hartig ${ }^{22}$. Aunque en normativas anteriores ya se pueden constatar los primeros resultados tangibles de esta influencia, fue la Ley de Ordenaciones de 1890 la que acabaría por imponer los rígidos criterios de la silvicultura alemana en España. El problema, como se constatará posteriormente, era que la ciencia dasonómica desarrollada en Alemania respondía a las características

21 J. Gómez Mendoza (1992), pp. 224-227.

22 J. Gómez Mendoza (1992), pp. 41-44, 219-220; con referencias más próximas, ver O. Elorrieta Artaza (1945), pp. 282-283. 
propias de bosques en los que la madera y la leña eran los aprovechamientos centrales y donde se desconocían producciones «secundarias» como la del corcho o la resina ${ }^{23}$. De este modo, bajo la dirección de L. Olazábal y Altuna, la gestión técnica y económica del monte público se someterá al principio genérico de «ordenar transformando», con absoluta prioridad para la producción de madera, relegando a este fin cualquiera de los restantes aprovechamientos ${ }^{24}$. La implantación de la normativa, sin embargo, iba a coincidir con el proceso de modernización y expansión de las industrias del corcho y la resina, lo cual no podía menos que contribuir a poner de manifiesto la falta de adecuación del sistema alemán a la realidad forestal española, siendo cada vez más frecuentes las críticas a la gestión impuesta por Olazábal ${ }^{25}$. En todo caso, como podremos constatar más adelante, ello no impidió que bajo el nuevo marco normativo, la industria resinera consiguiera sentar las bases de una de las etapas de más intensa expansión.

\section{Cambio normativo y procesos de trabajo}

Desde mediados del siglo XIX, la administración forestal trató de sustituir los complejos sistemas de aprovechamiento vecinal existentes en los montes españoles, imponiendo un nuevo marco normativo para la generalidad de los montes de propiedad pública ${ }^{26}$. Aunque existieron disposiciones que trataron de preservar determinados usos vecinales ${ }^{27}$, la

${ }^{23}$ La producción de resina en Alemania, al igual que en Rusia y otros países centroeuropeos, alcanzará cierto desarrollo con la aplicación de estimulantes químicos a partir de las experiencias realizadas mediados los años treinta (F. Nájera y Angulo, M. P. Rifé Lamprecht, 1951, pp. 13-15).

24 «Sólo prescriben un método de ordenación que denominan de ordenar transformando, y que se refiere indudablemente a la ordenación de montes con exclusivo aprovechamiento maderable. Nada se dice en ellas de otros métodos de ordenación, ni se ha previsto el aprovechamiento ordenado de las resinas y del corcho» (O. Elorrieta Artaza, 1945, p. 286)

25 J. Gómez Mendoza (1992), pp. 221-222.

${ }^{26}$ A excepción del País Vasco y Navarra, que tuvieron un desarrollo normativo diferenciado (para la comunidad autónoma vasca, ver J. M. Garayo Urruela, 1992, para Navarra, I. Iriarte Goñi, 1996).

27 El artículo 94 del Reglamento de 1865 establecía que «Todo aprovechamiento de productos forestales se adjudicará precisamente en subasta pública», exceptuando, entre otros, «Los productos de todo monte público que en virtud de usos o títulos legítimos reconocidos por la Administración estén considerados de aprovechamiento vecinal» $(H$. Del Campo, 1909, p. 65). 
adjudicación de los distintos aprovechamientos por medio de subasta pública, acabaría siendo el principal mecanismo para la privatización del uso del monte y la eliminación de los primitivos sistemas de asignación desarrollados por las comunidades campesinas ${ }^{28}$. Lo cual, necesariamente, fue un proceso largo y plagado de conflictos.

Tal como señalaron los forestalistas de la época, inicialmente, tanto en el aspecto normativo como en lo tecnológico, la industria resinera española estuvo guiada por métodos y sistemas introducidos desde Francia en la segunda mitad del siglo XIX ${ }^{29}$. En 1862, a partir de la iniciativa de La Resinera Segoviana, S. A., se aplicó por primera vez en España el llamado método Hugues, implantado previamente en las Landas de Francia. La resinación, de acuerdo con este nuevo sistema, venía a sustituir a los métodos tradicionales de resinación a muerte, pila o pino perdido, lo cual permitió una completa transformación del sector. La producción resinera dejó de ser una actividad artesanal, realizada de manera rudimentaria por campesinos con escasísimos recursos, para transformarse en un complejo industrial sólidamente implantado, especialmente en los montes de llanura de la meseta norte castellana ${ }^{30}$.

De acuerdo con el texto publicado por R. Xérica, en 1863 (Real Orden de 23 de abril) la administración dictó la primera disposición que imponía la resinación a vida mediante el sistema Hugues para aquellos montes cuyo aprovechamiento requería la aprobación del Ministerio de Fomento $^{31}$. Se fijó una altura máxima para las caras de 3,40 metros, dimensión que debía alcanzarse tras cinco años consecutivos de explo-

28 J.I. Jiménez Blanco (1991), p. 272.

29 Lo cual acabaría también provocando problemas de adecuación a la realidad forestal española: «al importar de Francia los métodos para verificar las labores de resinación y hasta los útiles para las mismas, creimos que impunemente podría implantarse también el método de cortas allí seguido, sin tener en cuenta la diferencia esencial que distingue a aquel clima y suelo, de los de Castilla, que es la humedad. Allí se puede cortar sin temor, a mata rasa, en la seguridad de que el repoblado natural abundante y si no el artificial, fácilmente conseguido, reproducían con admirable precisión el rodal aprovechado.

En España y en estos montes no sólo no hay repoblado natural tan abundante que automáticamente reproduzca el monte, sino que el artificial es difícil y muy caro, por no decir que hasta ahora por lo menos no se ha verificado, (salvo naturalmente en sitios de humedad), una repoblación completa de estos predios.»(J. Iturralde, O. Elorrieta, 1914, p. 67).

${ }_{30}$ Sobre la modernización tecnológica y la expansión de la industria resinera española, ver R. Uriarte Ayo (1995).

${ }^{31}$ R. Xérica (1869), p. 52. 
tación ${ }^{32}$. Su anchura debía ser de $12 \mathrm{~cm}$. en la base inferior y 11 en la superior, y la profundidad de 1 a $1,5 \mathrm{~cm} .{ }^{33}$ La normativa también establecía el calendario que había de seguirse en la ejecución de las labores. Así, los trabajos preparatorios del monte se iniciarían el 15 de febrero, la resinación daría comienzo el 1 de marzo y se prolongaría hasta el 30 de septiembre, finalizada ésta, la recolección definitiva de la miera, vasijas, etc., terminaría el 30 de octubre.

La Instrucción para la formación de los planes provisionales de aprovechamientos (Real Decreto de 17 de Mayo de 1865), incluía en su artículo 14 la obligación de los ingenieros redactores de detallar «convenientemente las prácticas seguidas en los montes para la extracción de los jugos de las coníferas, indicando las mejoras que se hayan introducido en las operaciones de recolección y que esta industria reclama en nuestro país» ${ }^{34}$. La experiencia acumulada y las opiniones vertidas por los propios ingenieros de distrito hizo que normativas posteriores tratasen de ajustar la legislación a los requerimientos observados, insistiendo en atajar las prácticas tradicionales todavía en uso.

En 1883 se aprobó un nuevo Pliego general de condiciones facultativas y reglamentarias para las subastas de aprovechamientos de resinas en los montes públicos (Real Orden de 17 de febrero) ${ }^{35}$. Dada la variedad climática existente en España y recogiendo los argumentos expuestos por el distrito de Segovia ${ }^{36}$, se autorizó a que fueran los propios distritos quienes estableciesen el calendario de la campaña, cuya duración, en todo caso, no podía exceder de los ocho meses y medio. Se reiteran iguales dimensiones para entalladuras y caras, fijándose, asimismo, períodos de cinco años para la ejecución completa de una cara. Así, los contratos de aprovechamiento deberían tener una duración mínima de cinco años y «en caso de extenderse a mayor número, deberá ser éste divisible en períodos de cinco» ${ }^{37}$. En los aspectos tecnológicos, la normativa fue particularmente explícita: 1) «No podrá señalarse

32 Puesto que el rendimiento del árbol tendía a disminuir a lo largo del ciclo, para mantener constante la producción anual, las entalladuras debían tener una dimensión creciente: $50 \mathrm{~cm}$. el primer año, $60 \mathrm{~cm}$. el segundo y tercero, $80 \mathrm{~cm}$. el cuarto y $90 \mathrm{~cm}$. el quinto (R. Xérica, 1869 , p. 52).

33 Sobre los métodos de trabajo, ver R. Uriarte Ayo (1995a), pp. 515-518.

34 J. B. Catalá y Gavilá, E. de las Cuevas y Rey (1913), p. 73.

35 H. Del Campo (1909), pp. 231-235.

36 H. Del Campo (1888), p. 203.

37 H. Del Campo (1909), p. 233. 
para ser resinado, pino alguno que no tenga al menos un diámetro de 25 centímetros a un metro de altura sobre el suelo» (art. 9), 2) «La resinación será a vida y la recolección de la miera se verificará por el sistema Hugues» (art. 9), 3) «No podrá, por consiguiente, verificar las operaciones conocidas con el nombre de dar retajo, sacar tea, abrir coqueras, o labrar, ni cortar ramas, ni bajar piñote o fruto de los pinos» (art. 10), 4) «deberá emplearse la escoda, quedando en absoluto prohibido el uso de azuelas antiguas» (art. 13).

Tal como señalábamos, la intervención de la administración forestal pretendía imponer las modernas técnicas y métodos de trabajo procedentes de Francia, arrinconado a quienes, apoyándose en las antiguas prácticas vecinales, trataban de resistir al cambio. Aquellas comunidades para las que el bosque constituía una fuente decisiva de ingresos complementarios, plantearon una soterrada resistencia a la imposición de una normativa que, en todo caso, modificaba las pautas tradicionales y limitaba su capacidad de control y decisión. Este fue el caso de pueblos como Zarzuela del Pinar, «peguero de abolengo, aferrado a las antiguas prácticas», que a pesar de las reiteradas multas impuestas a sus vecinos, «es el caso que la mayoría de los vecinos son completamente insolventes, y se obstinan en no buscar un sustento en la vida agrícola o jornalera alegando que si se les priva por los ingenieros de ejercer la industria resinera es tanto como condenarles a la miseria por no tener condiciones agrarias su término municipal ${ }^{38}$.

La resinación fraudulenta fue permanentemente denunciada por los ingenieros encargados de redactar los planes de aprovechamiento y fue preciso recurrir a la actuación de la guardia civil para controlarla y reprimir a sus protagonistas: «El Distrito ha tomado las disposiciones que su celo le ha sugerido para evitar las resinaciones fraudulentas, entre ellas la de reunir dos parejas de guardas en los cuarteles en que es más común tal abuso. Pero desgraciadamente, y por doloroso que sea confiarlo, el distrito carece de la fuerza necesaria para que dichas resinaciones se terminen. Los pueblos en cuyos montes tienen lugar las resinaciones ilegales no conocen otro medio de vivir y, por fuerte que parezca la frase, se pasan sin la aprobación superior para ejercer su industria. Se ha dado el caso, repetido más de una vez, de ir al monte los ingenieros, acompañados de la fuerza armada, destruirles los hornos

${ }^{38}$ AMA, Montes, 55/3, Segovia, 1885. 
para la fabricación de pez, y volver los pegueros a construirlos al día siguiente. Es su modo de ganar el sustento, y no se les podrá quitar sino estableciendo en los pueblos un puesto de guardia civil constante y numeroso. De no adoptar este medio no queda otro que el de transigir con los pegueros y tratar de regularizar su industria para que resulte el menor daño posible» ${ }^{39}$.

La dificultad de erradicar antiguas prácticas y sistemas de explotación llevó a que algunos ingenieros aconsejaran cambios normativos que permitieran su legalización: «Por tal razón, en el humilde sentir del Ingeniero que suscribe sería conveniente modificar con respecto a estos pueblos [Zarzuela del Pinar y Navas de Oro, entre ellos] el sistema de contratos que hoy se sigue para los aprovechamientos de resinas, dividiendo los montes de que se trata en pequeñas porciones cuya resinación se concedería por largos plazos, como se hacía antiguamente, con lo que en el país se llamaban matas. De esta suerte el arrendatario de cada mata o trozo de monte seguro de poder ejercer su industria por mucho tiempo, cuidaría la superficie que aprovechaba como cosa propia, puesto que a mayor esmero corresponderían mayores productos, y aun quizá de este modo fuera más fácil lograr que se acostumbraran a emplear el sistema moderno» ${ }^{40}$.

El problema tenía implicaciones tecnológicas, pues los resineros que se resistían a aceptar el nuevo modelo normativo siguieron practicando la resinación a muerte, haciendo uso de las tradicionales pegueras para la transformación de la miera obtenida: «Tanto de los reconocimientos practicados en el año último como los llevados a cabo en el actual [1889] en el monte "Común grande de las Pegueras" se deduce que los daños en él cometidos van en aumento y que para contenerles no hay otro dique que oponer a ese digámoslo así continuada resinación a muerte, que cual asoladora plaga va invadiendo todo el repoblado de cuarenta años arriba sin poder conseguir ni la Guardia Civil ni los empleados del Ramo contrarestarla aprehendiendo a los fraudulentos pegueros de Zarzuela del Pinar, a causa de que combinados todos ellos para el aviso de la entrada en el monte de cualquiera de aquellos, desaparecen aun teniéndolos a la vista, no hallando en la mayoría de los casos ni aun rastro de su segura presencia» ${ }^{41}$.

39 AMA, Montes, 7/4, Segovia, 1873.

40 AMA, Montes, 7/4, Segovia, 1874.

41 AMA, Montes, 91/4, Segovia, 1892. 
Incluso, cuando se consiguió imponer el sistema Hugues, no fue tarea fácil lograr que los resineros hicieran uso de las herramientas francesas en sustitución de las que tradicionalmente se empleaban en Castilla para la resinación a muerte. En este sentido, son igualmente frecuentes las denuncias de los ingenieros «por no usar algunos la escoda francesa y si a espaldas del Capataz y Guardia Civil, la azuela antigua, a cuyo destierro tiende por todos los medios el Distrito» ${ }^{42}$.

Mediada la década de los noventa, la presión ejercida por los intereses industriales (resina, corcho, madera, etc.) y la escasez de medios de las administraciones públicas, propició la aprobación de un marco legal particularmente ventajoso para los intereses de las empresas que actuaban en el sector forestal. Tal como reconocieron los propios industriales, la posibilidad de que los proyectos de ordenación fueran elaborados por particulares, el reconocimiento del derecho de tanteo en las subastas a los autores de los citados proyectos y la prolongación de los arrendamientos por espacio de veinte años, situación que se mantuvo entre 1894 y $1908^{43}$, fueron circunstancias decisivas en el devenir del sector ${ }^{44}$.

A partir de 1908, según Real Decreto de 24 de enero, se estableció que, en lo sucesivo, «no se otorgarán concesiones de estudios de Ordenación a particulares, Sociedades o Compañías», siendo la administración forestal la que deberá promover la elaboración de los proyectos que estime oportuno, bien sea por propia iniciativa o a instancia de particulares y entidades propietarias. A pesar de ello, aunque la preparación de los proyectos y los estudios preliminares se atribuye a la administración, «la inventariación y la formación de los proyectos se

42 AMA, Montes, 70/6, Segovia, 1888. El problema básico en este caso residía en que la azuela castellana no permitía ajustarse a las condiciones establecidas en cuanto a la dimensión y profundidad de las entalladuras, resultando siempre caras más anchas y profundas que las permitidas.

43 J. Gómez Mendoza (1992), p. 224.

44 «Lo escaso del personal y de los recursos pecuniarios que el estado dedicaba a estos trabajos, por una parte, y la presión que los elementos industriales - madereros, resineros y corcheros - ejercía en las altas esferas de la Administración, hizo que el estado admitiese la colaboración del interés privado en la redacción de los proyectos de ordenación de montes, dictando la ley de $1 .^{\circ}$ de junio de 1894 , por la que se consideraban las ordenaciones forestales como pertenecientes al primer grupo entre las que menciona el artículo $1 .^{\circ}$ de la ley general de Obras públicas de 1877 , con la que se dio a la vez a los concesionarios de estudios el derecho de tanteo en las subastas de aprovechamientos ordenados, subastas que alcanzaban períodos de veinte años, coincidentes con los de ordenación del monte» (Anónimo, 1930, p. 5). 
realizará por contrata, mediante subasta pública, si bien en casos especiales se podrá acordar que todos los estudios se verifiquen exclusivamente por administración ${ }^{45}$. La participación de particulares quedó definitivamente descartada con la entrada en vigor del Real decreto de 19 de febrero de 1924, según el cual «La preparación de los proyectos de Ordenación de los montes de interés general y sus estudios preliminares se llevarán a cabo únicamente, en lo sucesivo, por la Administración y por los Ayuntamientos, quedando abolida la contrata mediante subasta pública» ${ }^{46}$. Con posterioridad (Real Orden de 22 de mayo de 1924), se aprobaron nuevas Instrucciones para la formación de proyectos de ordenación de montes por cuenta de los Municipios, donde existe ya un articulado específico para los montes que se destinen a la producción de resina. De acuerdo con el primer artículo de las citadas Instrucciones, la duración de los proyectos de ordenación quedaba limitada a un decenio o «en caso necesario» a un quinquenio $^{47}$. En cuanto a los montes en resinación, se reconoce una amplia autonomía a los ingenieros de los respectivos distritos, de manera que, de acuerdo con el artículo 34, «Las dimensiones de las caras, así como su número y época de comienzo de la resinación y todos los datos esenciales de estas operaciones, se fijarán en el Reglamento especial de cada monte y formará parte del respectivo pliego de condiciones» ${ }^{48}$.

Constatada la dificultad de que la administración asumiera la realización de los proyectos de ordenación, una Real Orden de 11 de marzo de 1929 derogó las Instrucciones de 1924 y restableció provisionalmente las dictadas en 1890. Poco después, el 27 de enero de 1930, se aprobarían las Instrucciones para la ordenación y organización económica de la producción forestal, normativa que se mantuvo en vigor hasta la aprobación de las Instrucciones Generales para la Ordenación de los Arbolados, el 29 de diciembre de 1970. Las Instrucciones de 1930, mucho más elaboradas que las anteriores, contenían ya importantes novedades, fruto de la extensa experiencia acumulada en la gestión del monte público, tratando de ajustarse con mayor rigor a la rea-

${ }^{45}$ M. Martínez-Alcubilla, dir. (1923), t. XI, p. 583.

${ }^{46}$ M. Martínez-Alcubilla, dir. (1924), p. 335.

47 M. Martínez-Alcubilla, dir. (1924), p. 336.

48 M. Martínez-Alcubilla, dir. (1924), p. 338. 
lidad forestal española. Los estudios de ordenación, de nuevo, podrán ser elaborados «bien por la Administración forestal, o bien por los propietarios interesados» ${ }^{49}$ y la extracción de resinas queda ampliamente regulada en los artículos 151 a $160^{50}$.

\section{Geografía forestal y expansión productiva}

En el Cuadro IV se pueden observar los datos básicos referidos a la marcha de las explotaciones en los MUP ${ }^{51}$. La progresión de la industria resulta contundente, tanto en términos geográficos, penetrando en un número creciente de provincias, como productivos, aumentando las superficies, el número de árboles y la resina (miera) finalmente extraída. En cuanto a la ubicación y extensión de las masas forestales resinadas, queda claro que se trata de una actividad cuyo núcleo fundamental se encontraba en la meseta norte castellana. Segovia destaca de manera muy especial como eje indiscutible y permanente de la industria. Su hegemonía fue siempre clara, a pesar de que la expansión del sector significará una reducción relativa de su peso en el conjunto.

La inclusión de las explotaciones pertenecientes a particulares no va a alterar esta realidad. Aunque no podemos precisar con exactitud qué proporción de resina era obtenida en los MUP, ciertamente, a diferencia de lo que ocurría con otras producciones ${ }^{52}$, se trataba de un

49 M. Martínez-Alcubilla, dir. (1930), p. 325.

${ }_{50}$ Un detallado estudio del método de ordenación seguido en los proyectos de principios de siglo puede verse en J. Iturralde y O. Elorrieta (1914), pp. 50-86; un trabajo posterior, A. Cid Ruiz-Zorrilla (1941). Sobre los sistemas de ordenación contemporáneos, ver A. Madrigal Collazo (1994).

${ }_{51}$ Las series han sido elaborados a partir de las EGPMUP, salvo en los años 1916-1917 y 1920-1921 que proceden del Anuario Estadístico de España para los correspondientes años. Al manejar los datos provinciales, se han podido detectar cierto número de errores en las sumas de los agregados finales y diferencias con totales de distintas columnas. Cuando ha sido posible, se han realizado las correcciones oportunas, de ahí que en determinados años puedan existir pequeñas discrepancias con respecto a series publicadas con anterioridad.

${ }_{52}$ En el caso del corcho, según estimaciones realizadas por S. Zapata Blanco (1986), pp. 235-236, la producción de los alcornocales públicos debía representar en torno al 15 o 16 por ciento del total, de lo cual «se deduce que la mayoría de los alcornocales pertenecían a particulares, careciendo de fiabilidad, por lo tanto, cualquier estimación de la producción total obtenida como el producto de la correspondiente a los montes de utilidad pública por un coeficiente». 
aprovechamiento en el que la contribución del patrimonio público fue siempre decisiva. De forma ocasional, las propias EGPMUP nos proporcionan datos sobre la producción de los montes privados ${ }^{53}$, sin

CUADRo II

DISTRIBUCIÓN PROVINCIAL DE LA INDUSTRIA RESINERA. NÚMERO DE PINOS EN EXPLOTACION EN 1929

\begin{tabular}{lrrrrr}
\hline \multicolumn{1}{c}{ Provincias } & \multicolumn{2}{c}{ Pinos explotados } & Total (3) & \% 1/3 & \% 2/3 \\
& Públicos (1) & Privados (2) & & & \\
\hline Albacete & 1.044 .804 & 0 & 1.044 .804 & 100,00 & 0,00 \\
Almería & 35.000 & 205.000 & 240.000 & 14,58 & 85,42 \\
Ávila & 1.114 .008 & 636.202 & 1.750 .210 & 63,65 & 36,35 \\
Burgos & 875,283 & 437,933 & 1.313 .216 & 66,65 & 33,35 \\
Cáceres & 26.411 & 136.686 & 163.097 & 16,19 & 83,81 \\
Cuenca & 535.476 & 2.638 .491 & 3.173 .967 & 16,87 & 83,13 \\
Granada & 141.454 & 376.911 & 518.365 & 27,29 & 72,71 \\
Guadalajara & 1.095 .191 & 983.267 & 2.078 .460 & 52,69 & 47,31 \\
León & 353.214 & 17.532 & 370.746 & 95,27 & 4,73 \\
Madrid & 125.103 & 230.533 & 355.636 & 35,18 & 64,82 \\
Málaga & 62.650 & 190.000 & 252.650 & 24,80 & 75,20 \\
Murcia & 31.700 & 181.491 & 213.191 & 14,87 & 85,13 \\
Orense & 0 & 20.000 & 20.0000 & 0,00 & 100,00 \\
Segovia & 1.665 .373 & 1.015 .410 & 2.680 .783 & 62,12 & 37,88 \\
Soria & 1.060 .391 & 476.985 & 1.537 .376 & 68,97 & 31,03 \\
Teruel & 678.376 & 138.811 & 817.187 & 83,01 & 16,99 \\
Valencia & 111.200 & 0 & 111.200 & 100,00 & 0,00 \\
Valladolid & 671.208 & 364.257 & 1.035 .465 & 64,82 & 35,18 \\
Zaragoza & 150.742 & 160.000 & 310.742 & 48,51 & 51,49 \\
\hline \multicolumn{1}{c}{ Total } & $\mathbf{9 . 7 7 7 . 5 8 6}$ & $\mathbf{8 . 2 0 9 . 5 0 9}$ & $\mathbf{1 7 . 9 8 7 . 0 9 5}$ & $\mathbf{5 4 , 3 6}$ & $\mathbf{4 5 , 6 4}$ \\
\hline & & & & & \\
\hline
\end{tabular}

Fuente: Instituto forestal de investigaciones y experiencias, p. 23.

53 Aunque, insistimos, los datos no reflejan la realidad del sector, para los años 1922 1923, 1923-1924, 1924-1925 y 1925-1926, se informa de la producción de resina y su distribución provincial, mientras que para 1926-1927, 1927-1928 y 1928-1929, se informa del número de pinos resinados y su distribución provincial. 
embargo su escasa calidad, al menos en lo que se refiere al número de pinos y a la superficie explotada, desaconsejan su empleo. A nuestro juicio, habrá que esperar a las estadísticas oficiales elaboradas por el Consorcio Resinero para la campaña de 1929, para tener una idea más exacta del reparto de la propiedad y la distribución territorial del sector ${ }^{54}$.

De acuerdo con estos datos (Cuadro II), los montes públicos aportaron en la citada fecha un $54,36 \%$ del total de pinos resinados, lo cual refleja con claridad la importancia del patrimonio público en la industria resinera. En cuanto a su distribución territorial, se reafirma la hegemonía castellana y la de la provincia de Segovia en particular. Las cifras globales relativas a la producción de miera extraída en montes públicos y privados, y los rendimientos medios alcanzados por unidad explotada (Cuadro II), añaden nuevas evidencias. Aunque la resinación llegó a introducirse en numerosas provincias españolas, las zonas que realmente desarrollaron una actividad significativa se encuentran ubicadas en el centro y norte de la meseta castellana, destacando de manera muy particular el caso de Segovia, cuya participación en la producción de miera se acerca al $25 \%$ del total. Si añadimos las producciones de Ávila y Soria, tendríamos prácticamente la mitad de la industria. Por otro lado, queda también de manifiesto la existencia de importantes contrastes en los rendimientos unitarios obtenidos en cada una de las diferentes zonas. Así, Segovia, con unos coeficientes que prácticamente duplican la media, se sitúa de nuevo a la cabeza, logrando una cuota de producción del $24,1 \%$ con el $14,86 \%$ de los pinos resinados. Cuenca, por el contrario, aun siendo una de las principales áreas productoras, tiene unos rendimientos unitarios muy por debajo de la media, de forma que, para alcanzar una cuota del 9,7\% en la producción, requiere la explotación del 17,65\% del total de pinos resinados.

Los factores que determinan el rendimiento de las diferentes masas forestales son de muy diversa naturaleza, afectando, a igual tecnología,

${ }^{54}$ Los datos fundamentales pueden verse en Instituto forestal de investigaciones y experiencias (1931) y M. Tomeo (1939). A pesar de que no se trata de diferencias sustanciales, lo cierto es que tampoco en este caso existe una coincidencia plena en las cifras, así mientras Tomeo contabiliza un total de 18.029.333 pinos en explotación, la cifra del Instituto es de 17.987.095. Dado que ni en un caso ni en otro se nos ofrece una información completa, el Cuadro I ha sido elaborado a partir de los datos que aporta el Instituto, mientras que el Cuadro II parte de los datos de Tomeo. 
CUADro III

DISTRIBUCIÓN PROVINCIAL DE LA INDUSTRIA RESINERA. PRODUCCIÓN DE MIERA, PINOS EXPLOTADOS Y RENDIMIENTOS EN 1929

\begin{tabular}{|c|c|c|c|c|c|}
\hline Provincias & $\begin{array}{l}\text { Producción } \\
\text { (kg.) }\end{array}$ & N. ${ }^{\circ}$ pinos & $\begin{array}{c}\text { Producción } \\
(\%)\end{array}$ & $\begin{array}{c}\text { N. }{ }^{\circ} \text { pinos } \\
(\%)\end{array}$ & $\begin{array}{l}\text { Rendimiento } \\
\text { (kg. pino/año) }\end{array}$ \\
\hline Albacete & 2.765 .671 & 1.044 .804 & 5,6 & 5,79 & 2,647 \\
\hline Almería & 399.148 & 240.000 & 0,9 & 1,33 & 1,663 \\
\hline Ávila & 5.995 .632 & 1.782 .541 & 12,3 & 9,88 & 3,435 \\
\hline Burgos & 3.308 .711 & 1.313 .216 & 6,8 & 7,28 & 1,923 \\
\hline Cáceres & 382.681 & 130.686 & 0,8 & 0,72 & 2,799 \\
\hline Cuenca & 4.687 .524 & 3.183 .874 & 9,7 & 17,65 & 1,476 \\
\hline Granada & 936.184 & 518.365 & 1,9 & 2,87 & 1,806 \\
\hline Guadalajara & 4.146 .250 & 2.078 .460 & 8,6 & 11,52 & 2,038 \\
\hline León & 986.855 & 370.746 & 2,0 & 2,05 & 2,661 \\
\hline Madrid & 195.835 & 355.636 & 1,8 & 1,97 & 2,496 \\
\hline Málaga & 258.226 & 252.650 & 0,6 & 1,40 & 1,022 \\
\hline Murcia & 511.944 & 213.191 & 1,0 & 1,18 & 2,401 \\
\hline Orense & & 20.000 & & 0,1 & \\
\hline Salamanca & 102.397 & 26.411 & 0,2 & 0,14 & 3,877 \\
\hline Segovia & 11.711 .387 & 2.680 .783 & 24,1 & 14,86 & 4,491 \\
\hline Soria & 5.509 .386 & 1.537 .376 & 11,3 & 8,52 & 2,608 \\
\hline Teruel & 1.764 .442 & 817.187 & 3,7 & 4,53 & 2,097 \\
\hline Valencia & 48.744 & 111.200 & 0,1 & 0,61 & 0,812 \\
\hline Valladolid & 3.643 .511 & 1.035 .465 & 7,5 & 5,79 & 3,212 \\
\hline Zaragoza & 395.491 & 310.742 & 0,8 & 1,72 & 2,727 \\
\hline
\end{tabular}

Fuente: M. Tomeo (1939), pp. 27-29.

las condiciones climáticas, la calidad de los suelos, su orografía, la especie arbórea resinada, el estado general de la masa en su conjunto y las formas de gestión que en cada caso se utilicen. Aunque la representación incluida en las Figuras 1 y 2 contiene algunas excepciones, tal como observó M. Tomeo, si ubicamos los rendimientos medios provinciales de acuerdo con los datos contenidos en el Cuadro II, vemos que existe cierta regularidad en su distribución territorial, formándose espacios concéntricos con un núcleo de máximo rendimiento situado en

$$
-671-
$$




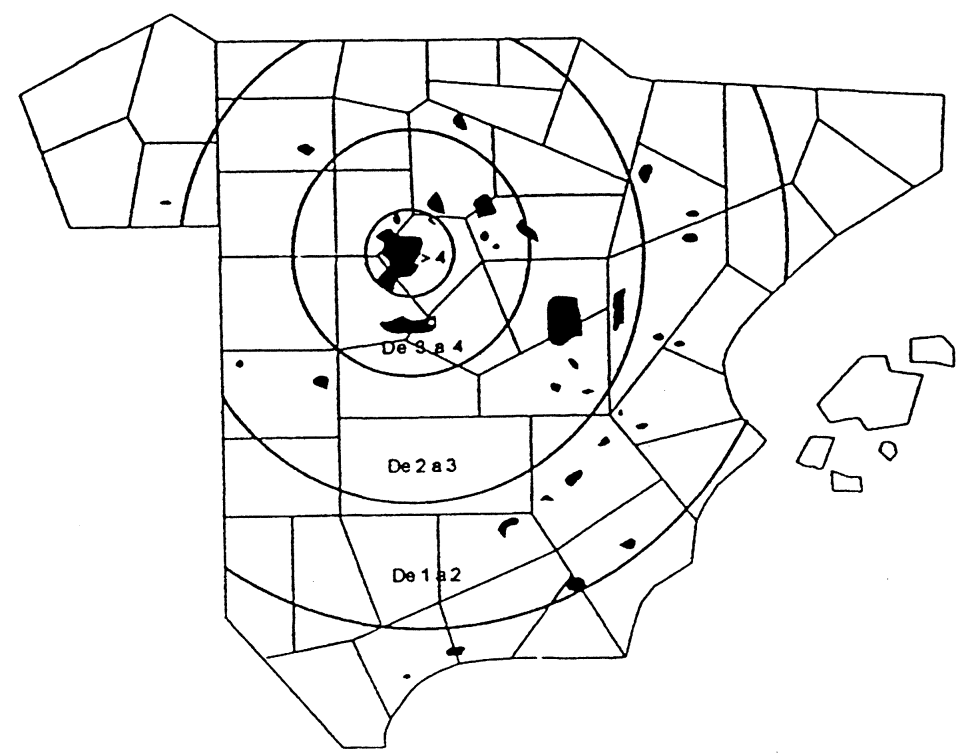

FIGURA 1.-Masas forestales resinadas y distribución aproximada de rendimientos (kg. resina pino/año).

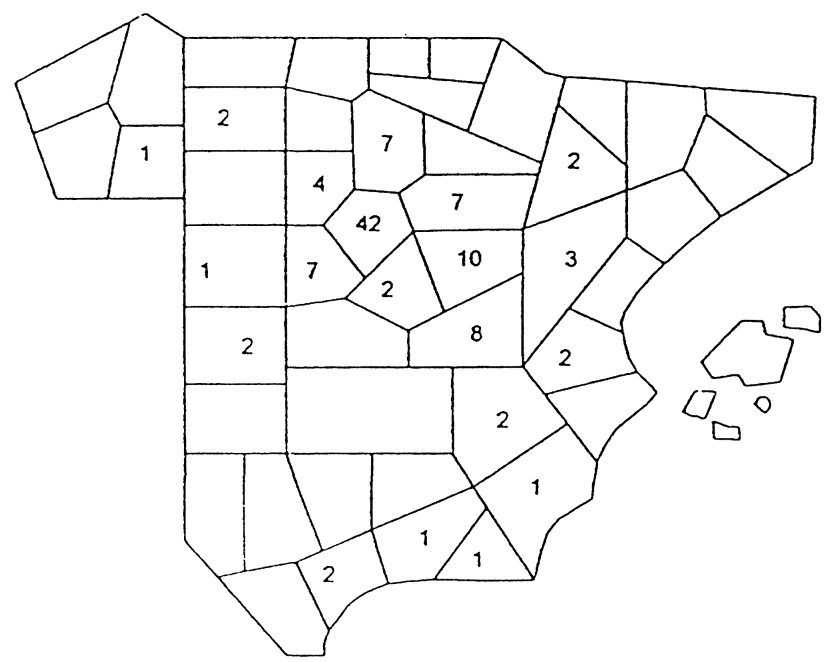

FIgURA 2.-Distribución provincial de empresas resineras en 1929.

$-672-$ 
la región segoviana ${ }^{55}$. Parece claro que las llanuras interiores y elevadas de Castilla la Vieja reunían las condiciones óptimas para el desarrollo de la industria resinera. De hecho, sabemos que, históricamente, su expansión ha partido del núcleo citado, se ha extendido hacia otras regiones cuando las circunstancias del mercado lo han permitido y, finalmente, invirtiendo el anterior recorrido, la industria ha ido abandonando las zonas marginales conquistadas en último lugar, para refugiarse, de forma ya residual desde los años setenta, en sus lugares originarios ${ }^{56}$.

Con datos únicamente referidos a los MUP, las estadísticas oficiales permiten reconstruir con relativa precisión el proceso expansivo del sector, reflejado tanto en la producción final de miera, como en la superficie ocupada por el aprovechamiento y el número de pinos sometidos a resinación (Cuadro IV). Los coeficientes obtenidos indican, en sus fluctuaciones, la oscilación lógica de un producto cuya cosecha, al igual que en cualquier otro cultivo agrario, está muy determinada por las constantes variaciones en las condiciones meteorológicas y otras circunstancias difíciles de prever ${ }^{57}$. Así, el elevado rendimiento unitario alcanzado en el año 1916-1917, permitió a $L U R E$ recolectar $1.932 .781 \mathrm{~kg}$. más de miera que en la campaña anterior, habiendo resinado 77.866 pinos menos, lo cual era atribuido a que «en el rendimiento del pino influyen decisivamente los estados meteorológicos, y más especialmente el que rija durante la primavera» ${ }^{58}$. A su vez la caída que se produjo al

55 Madrid y Burgos tendrían rendimientos inferiores a los de la zona donde se ubican en razón de las «especiales circunstancias de suelo, clima, orientación, etc»; en el caso de Cuenca sus escasos rendimientos son debidos a la presencia mayoritaria en sus suelos del pino laricio, mientras que en los casos de Albacete y Murcia, el pino carrasco permitía superar los rendimientos del pinaster (M. Tomeo, 1939, p. 31).

56 Sobre la fase final de la industria resinera española, ver R. Uriarte Ayo (1999).

57 «Aunque operáramos siempre sobre el mismo número de pinos y estos fueran de igual rendimiento, las cantidades de miera que se obtendrían anualmente serían diferentes, por la influencia que tienen en la producción las aguas que se almacenan en el subsuelo durante el invierno y primavera; la temperatura reinante en el transcurso del año forestal; las oscilaciones de dicha temperatura; la cantidad de lluvia caida durante la explotación y distribución. A esas causas de variación de cantidad recogible, causas que son independientes de la acción del hombre, hay que añadir multitud de otras que dependen de éste y caen dentro de las llamadas voluntarias, como son las huelgas, las faltas de personal obrero, sea por expatriación, por dedicarse a otras faenas, por enfermedades, por desplegar mayor o menor celo en el cumplimiento de su misión, etcétera.» (Memoria LURE 1918-1919, p. 5).

58 Ibídem. 
CUAdro IV

PRODUCCIÓN DE MIERA, PINOS EXPLOTADOS, SUPERFICIE APROVECHADA Y RENDIMIENTOS EN MONTES DE UTILIDAD PÚBLICA (1900-1933)

\begin{tabular}{lcccccc}
\hline Años & $\begin{array}{c}\text { (1) } \\
\text { Pinos }\end{array}$ & $\begin{array}{c}\text { (2) } \\
\text { Superficie } \\
\text { (número) }\end{array}$ & $\begin{array}{c}\text { (ha) } \\
\text { Producción } \\
\text { (kg.) }\end{array}$ & $\begin{array}{c}\text { Rendi- } \\
\text { mientos } \\
\mathbf{( 3 / 1 )}\end{array}$ & $\begin{array}{c}\text { Rendi- } \\
\text { mientos } \\
\mathbf{( 3 / 2 )}\end{array}$ & $\begin{array}{c}\text { Pinos por } \\
\text { hectárea } \\
\mathbf{( 1 / 2 )}\end{array}$ \\
\hline $1900-1901$ & 2.659 .368 & 45.424 & 8.069 .722 & & & 58,55 \\
$1901-1902$ & 2.910 .822 & 50.244 & 8.469 .478 & & & 57,93 \\
$1902-1903$ & 2.956 .060 & 55.582 & 7.652 .209 & & & 53,18 \\
$1903-1904$ & 2.993 .864 & 59.702 & 9.433 .293 & & & 50,15 \\
$1904-1905$ & 3.188 .569 & 63.368 & 9.690 .269 & & & 50,32 \\
$1905-1906$ & 3.374 .446 & 66.940 & 9.873 .941 & & & 50,41 \\
$1906-1907$ & 3.374 .812 & 68.119 & 9.741 .717 & & & 49,54 \\
$1907-1908$ & 4.674 .171 & 70.250 & 14.069 .129 & & & 66,54 \\
$1908-1909$ & 3.942 .046 & 77.171 & 9.874 .814 & & & 51,08 \\
$1909-1910$ & 4.298 .814 & 93.336 & 11.526 .283 & & & 46,06 \\
$1910-1911$ & & & & & & \\
$1911-1912$ & 4.281 .685 & 100.598 & 12.218 .220 & 2,85 & 121,46 & 42,56 \\
$1912-1913$ & 4.768 .785 & 105.792 & 11.554 .015 & 2,42 & 109,21 & 45,08 \\
$1913-1914$ & 4.721 .599 & 115.138 & 11.767 .618 & 2,49 & 102,20 & 41,01 \\
$1914-1915$ & 4.952 .451 & 95.768 & 12.634 .183 & 2,55 & 131,92 & 51,71 \\
$1915-1916$ & 5.481 .821 & 92.496 & 15.055 .345 & 2,75 & 162,77 & 59,27 \\
$1916-1917$ & 5.813 .156 & 107.015 & 16.796 .026 & 2,89 & 156,95 & 54,32 \\
$1917-1918$ & 5.970 .333 & 105.958 & 13.429 .487 & 2,25 & 126,74 & 56,35 \\
$1918-1919$ & 5.669 .476 & 104.340 & 13.104 .347 & 2,31 & 125,59 & 54,34 \\
$1919-1920$ & 6.677 .579 & 132.512 & 14.882 .342 & 2,23 & 112,31 & 50,39 \\
$1920-1921$ & 6.361 .656 & 127.106 & 15.387 .478 & 2,42 & 121,06 & 50,05 \\
$1921-1922$ & 6.391 .314 & 136.075 & 16.352 .818 & 2,56 & 120,18 & 46,97 \\
$1922-1923$ & 7.659 .442 & 142.789 & 19.955 .473 & 2,61 & 139,75 & 53,64 \\
$1923-1924$ & 7.220 .526 & 139.309 & 18.726 .267 & 2,59 & 134,42 & 51,83 \\
$1924-1925$ & 7.903 .081 & 156.840 & 19.737 .733 & 2,50 & 125,85 & 50,39 \\
$1925-1926$ & 8.776 .182 & 204.077 & 21.279 .487 & 2,42 & 104,27 & 43,00 \\
$1926-1927$ & 9.656 .325 & 211.693 & 23.767 .703 & 2,46 & 112,27 & 45,61 \\
$1927-1928$ & 9.799 .845 & 224.147 & 26.667 .054 & 2,72 & 118,97 & 43,72 \\
$1928-1929$ & 10.051 .083 & 237.606 & 24.583 .404 & 2,45 & 103,46 & 42,30 \\
$1929-1930$ & & & 26.246 .000 & & & \\
$1930-1931$ & 10.119 .816 & 242.878 & 26.500 .386 & 2,62 & 109,11 & 41,67 \\
$1931-1932$ & & 235.508 & 26.888 .862 & & 114,17 & \\
$1932-1933$ & 11.064 .322 & 236.186 & 26.409 .887 & 2,39 & 111,82 & 46,85 \\
\hline & & & & & &
\end{tabular}

Fuente: véase nota 50 . 
año siguiente fue consecuencia de los conflictos laborales, que «siempre producen pérdidas de trabajo que conllevan una minoración en la obtención de producto recolectado, y del otro, y como factor principal, las pésimas condiciones climatológicas ocurridas en el comienzo de la campaña» 59 .

Sin embargo, también puede apreciarse un cierto movimiento derivado de la propia dinámica expansiva. Tras la generalización del método Hugues, técnicamente las operaciones de resinación apenas sufrirán cambios significativos hasta que se ensayaron procedimientos nuevos en los años sesenta (pica de corteza con empleo de estimulantes químicos, nuevas grapas, etc.) ${ }^{60}$. Con una tecnología prácticamente constante, el incremento en la producción equivalía a extender el área de explotación y el número de pinos tratados (Fig. 3) ${ }^{61}$.

Por regla general, tal como se ha dicho, la ampliación de los aprovechamientos partía de aquellas zonas mejor dotadas para extenderse sobre espacios que cada vez planteaban mayores dificultades de extracción o transporte, o menores rendimientos. Las primeras masas forestales resinadas fueron las que garantizaban producciones unitarias más altas y, a medida que la actividad afectó a nuevas zonas, fue necesario poner en explotación pinares cuyo rendimiento era apreciablemente menor. De este modo, como fue observado por J. Sanz Fernán$\mathrm{dez}^{62}$, el rendimiento medio por hectárea explotada pudo experimentar un cierto retroceso (Fig. 4), obligando a que los incrementos en extensión fueran cada vez más importantes. El desajuste, sin embargo, tan

${ }^{59}$ Memoria LURE 1917-1918, p. 7.

60 Aunque la tecnología, en lo que se refiere a los aspectos forestales, no sufrió modificaciones drásticas hasta los años sesenta, siempre existió un cierto margen para la introducción de mejoras que permitían incrementar los rendimientos. La dirección de LURE, al finalizarar los años veinte, señalaba que el aumento progresivo en los rendimientos era resultado de «un mayor esmero en las labores de monte. Paulatinamente, con tenacidad y constancia, van venciendose los prejuicios y rutinas que predominaban en las operaciones de resinación, los que, por lo inveterados, resultan de difícil correción. La forma racional de practicar la «pica»; el acierto en la distribución de pinos adjudicando a cada resinero el número proporcional a su capacidad de trabajo; menudear las remasas para evitar la pérdida de miera; disposición en la colocación del crampón, etc, son factores que influyen poderosamente en la producción y a ello se atiende preferentemente por nuestro personal técnico y de guardería» (Memoria LURE 1928, p. 6).

${ }^{61}$ No se incluye el índice de producción para el período inicial dado que las cifras de base han sido previamente estimadas de acuerdo con los rendimientos medios conocidos para el período 1910-1911/1915-1916.

${ }^{62}$ J. Sanz Fernández (1986), pp. 151-153. 


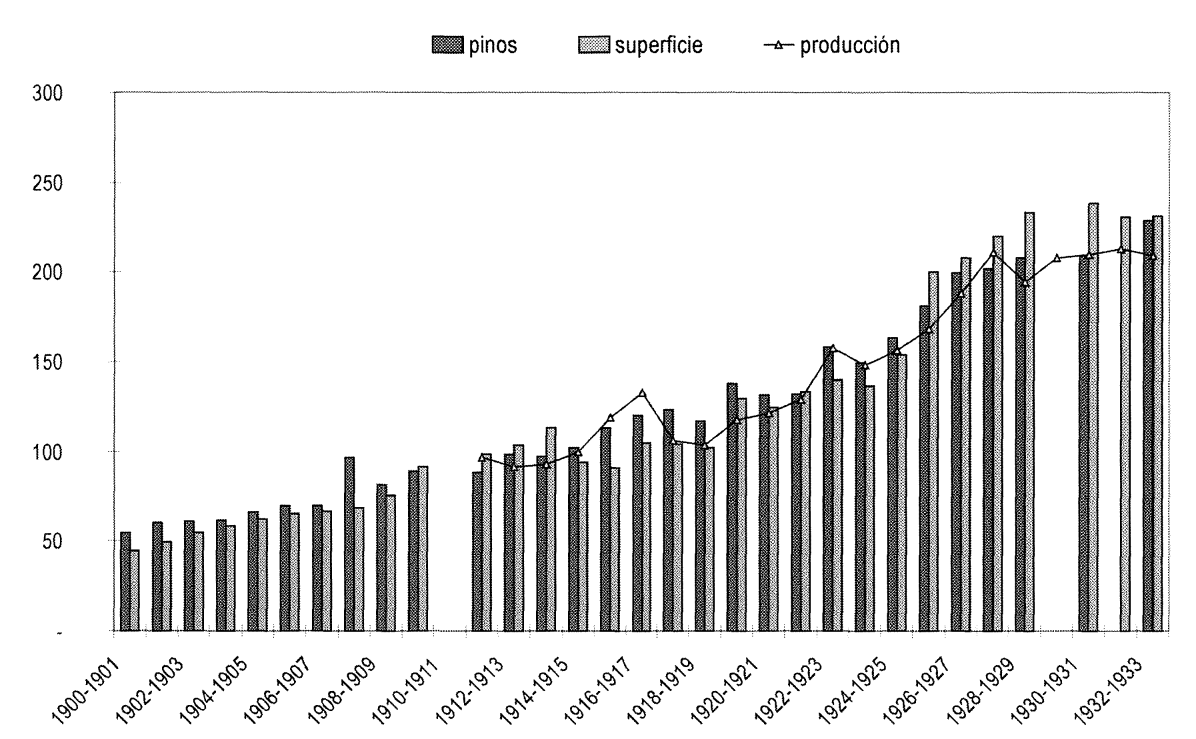

FIGURA 3.-Índices de producción de miera, pinos resinados y superficie en aprovechamiento en Montes de Utilidad Pública

$(1911-1912 / 1915-1916=100)$,

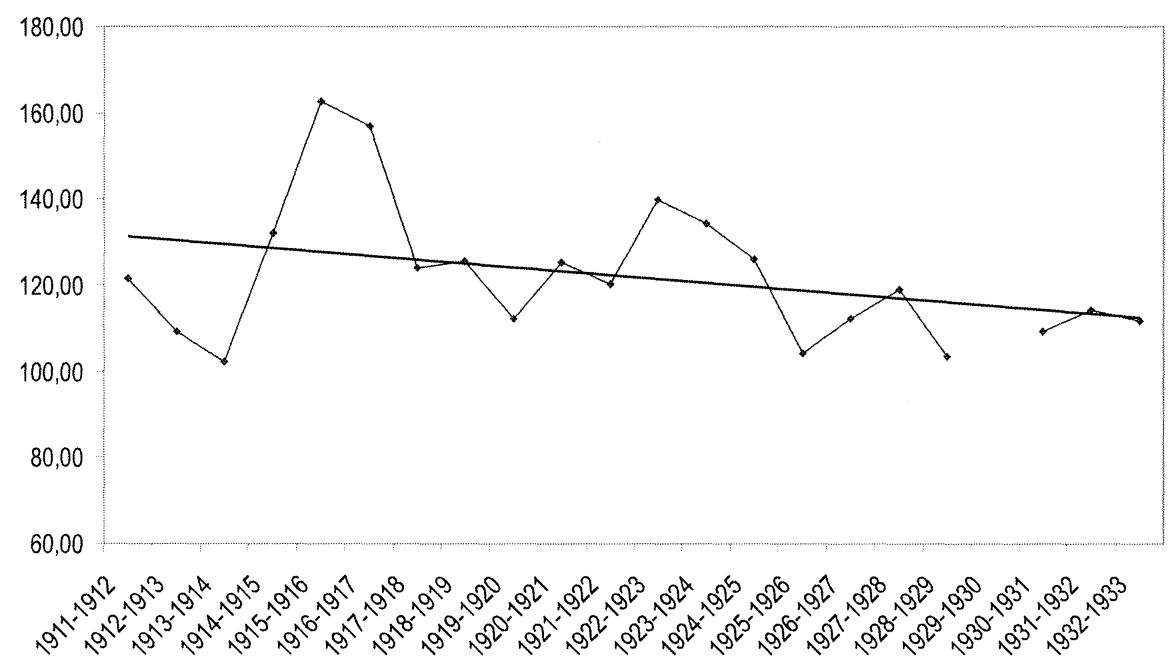

Figura 4.-Rendimientos unitarios en Montes de Utilidad Pública ( $k g$. de miera por hectárea y año). 
sólo se hizo patente mediados los años veinte. Por otro lado, en el producto medio obtenido por árbol y año apenas se observan rendimientos decrecientes, y sus oscilaciones serían más bien resultado de unas cosechas que varían en función de las condiciones climatológicas de cada campaña (Fig. 5). De este modo, dado que los arrendamientos se establecían de acuerdo con el número de pinos explotados, la estrategia que al parecer se siguió, en especial a partir del proceso expansivo de los años veinte, trataba de garantizar precisamente la producción unitaria por árbol resinado, disminuyendo su número por unidad de superficie aprovechada (Fig. 6) y concentrando las labores en el arbolado mejor dotado. En este sentido, los criterios que guiaban la actuación de los ingenieros forestales, lejos de descuidar la evolución de los rendimientos, al tiempo que preservaban los intereses de los industriales del sector, respondían con coherencia al principio de regularización de la producción planteado como objetivo en la normativa del sistema ordenador.

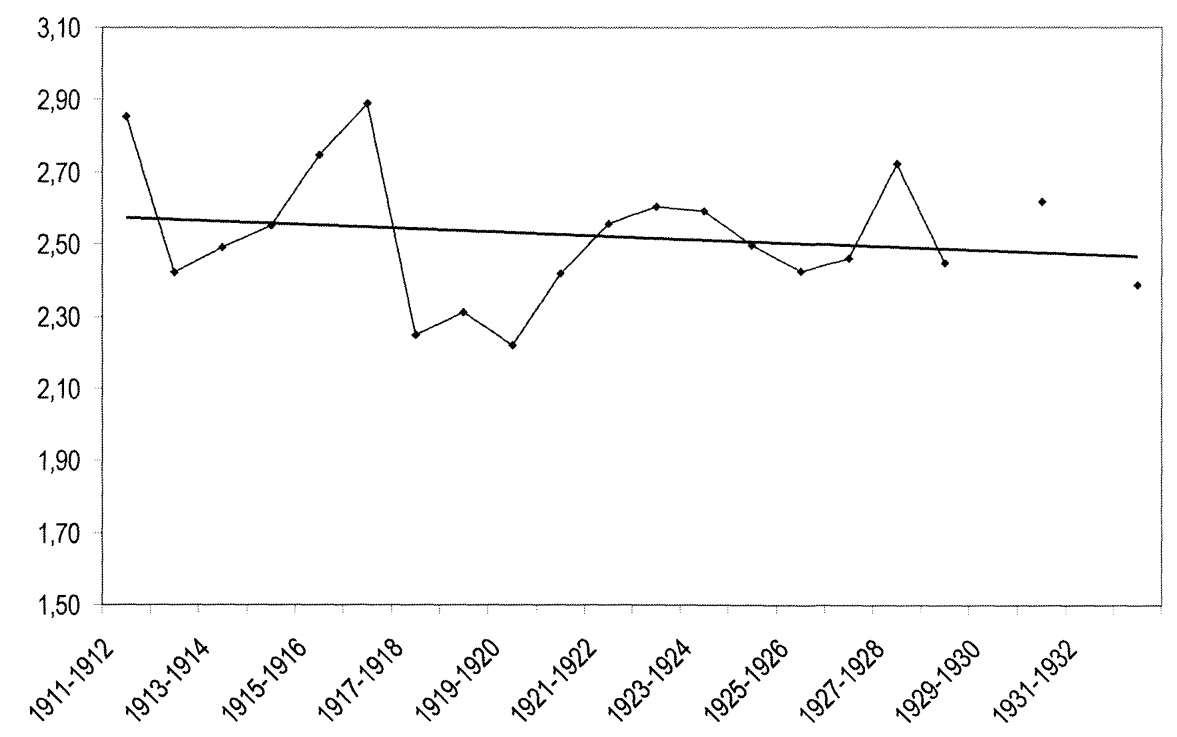

Figura 5.-Rendimientos unitarios en Montes de Utilidad Pública ( $k g$. de miera por pino y año). 


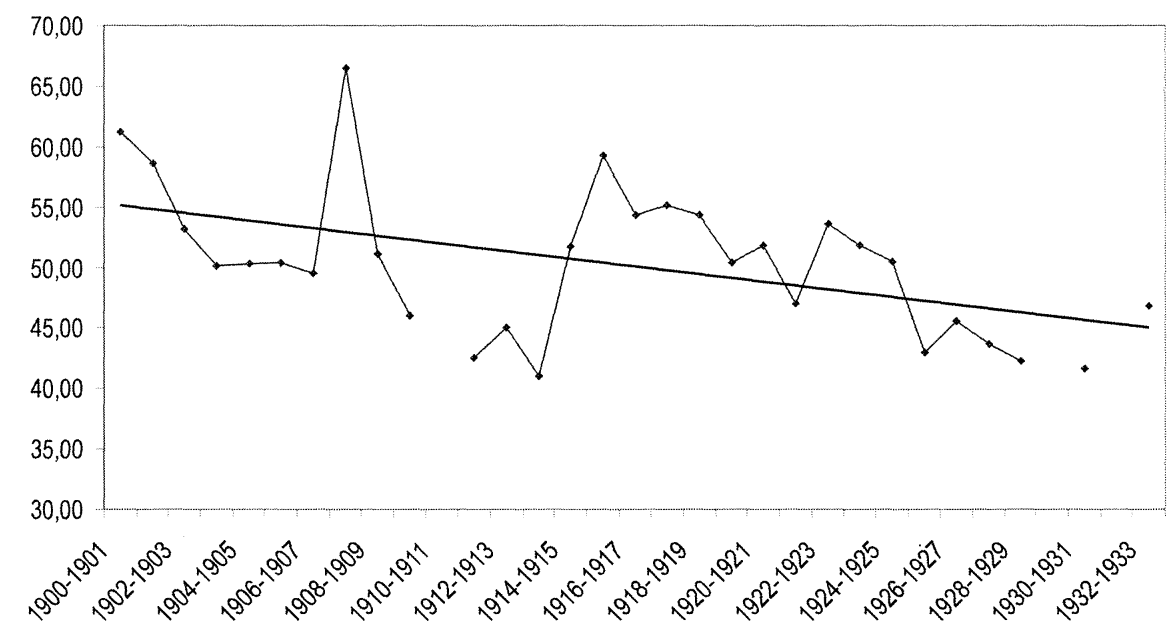

FIGURA 6.-Número de pinos resinados por hectárea de superficie en aprovechamiento en Montes de Utilidad Pública.

Aunque resulte más complejo determinarlo, los rendimientos podían estar condicionados por el régimen de propiedad o los métodos de gestión aplicados en cada caso. Cuando se empleaban trabajadores a destajo, remunerados en función de la miera extraída, el operario trataba de alcanzar rendimientos unitarios más elevados, para lo cual, si no se estrechaba la vigilancia, tendía a incrementar la dimensión de las entalladuras por encima de lo que permitían las disposiciones vigentes ${ }^{63}$. Si tenemos en cuenta que «la producción por árbol disminuye con el aumento de la espesura» ${ }^{64}$, es posible que las explotaciones escasamente intervenidas, ya fueran públicas o privadas, tuvieran menores rendimientos por árbol resinado, aunque, dependiendo de las circunstancias, los rendimientos por unidad de superficie serían superiores. Los pinos pertenecientes a propietarios particulares solían ser resinados, por lo general, a partir de diámetros menores que los pertenecientes a entidades públicas, lo cual también debía incidir en el rendimiento. En lo que se refiere a los montes públicos las EGPMUP señalan reite-

${ }^{63}$ Memoria LURE 1924-1925, p. 5.

${ }^{64}$ EGPMUP 1911-1912, p. xxiii. 
radamente que los mayores rendimientos obtenidos en los montes ordenados eran debidos a que, por lo general, «fueron elegidos por reunir mejores condiciones para producir esa materia prima, hoy tan solicitada en el mercado» ${ }^{65}$. La diferencia, asimismo, era debida a que en los montes ordenados la resinación «se verifica en todos los pinos que tienen dimensiones reglamentarias. En los montes de los distritos los lotes de resinación se forman de árboles de las mayores dimensiones en diámetro, para que puedan resistir más número de años, resultando resinación por entresaca; la idea que informa este criterio es el de máxima conservación del vuelo, obteniendo la posibilidad de miera como producto principal, y de madera y leñas solo limitada a los pinos caídos por el viento o agotados por las labores» ${ }^{66}$. En definitiva, aunque la diversidad de circunstancias locales podía alterar notablemente las posibilidades concretas de cada zona, en su conjunto, la extracción de resina se consolidó como uno de los aprovechamientos de mayor peso en la industria forestal española contemporánea.

\section{Conclusiones}

Salvo en superficies forestales muy intervenidas, los bosques suministran de forma espontánea y simultáneamente una oferta diversificada de productos y aprovechamientos posibles. Con frecuencia, especialmente en sociedades preindustriales, esta circunstancia puede permitir un uso «múltiple e integrado» del monte ${ }^{67}$, por lo general subordinado a las necesidades reproductivas de las economías campesinas. Sin embargo, a medida que se imponen las necesidades de empresas y sectores industriales específicos, cierto grado de especialización productiva resulta inevitable. Dificultades técnicas y normativas impiden optimizar producciones complejas, de modo que acaba siendo necesario definir un uso preferente y subordinar el resto a las prioridades que impone el aprovechamiento principal ${ }^{68}$.

Tal y como se recoge en los planes de ordenación elaborados para las zonas donde se introdujo la industria resinera, el pinar podía orientarse

${ }^{65}$ EGPMUP 1911-1912, p. xxiii.

${ }^{66}$ EGPMUP 1912-1913, p. xxx.

${ }^{67}$ H. Groome (1989), p. 142.

68 A. Madrigal Collazo (1992), p. 104. 
a la extracción de madera, resina, fruto, pasto, brozas, etc. En la medida de lo posible, se trató de hacer compatibles los distintos aprovechamientos mencionados. Sin embargo, a pesar de que la resina ha sido considerado un aprovechamiento «secundario», siendo la madera el aprovechamiento «principal», la expansión de la demanda y de los precios, hizo que la extracción de miera alcanzara una clara hegemonía en las regiones forestales donde predominaba el pino negral (pinaster).

A ello ha contribuido decisivamente la propia administración, sobre todo a partir de los años veinte, una vez que se impusieron criterios eminentemente productivistas en la gestión del monte público. Sin embargo, la extensión de la industria resinera estuvo siempre muy vinculada a intereses empresariales privados. De hecho, la resina, junto con el corcho, ha sido uno de los sectores en los que España ha logrado una importante presencia internacional, lo cual, sin duda, abrió expectativas y generó oportunidades de inversión para la iniciativa privada. Por otro lado, a diferencia de lo que ocurre en aquellas producciones forestales que requieren largos períodos de rotación, la extracción de resina se desarrolla en ciclos cortos, lo cual también ha favorecido la presencia y el interés del capital privado.

El proceso expansivo que hemos podido constatar constituyó, en todo caso, un capítulo básico del complejo proceso de integración del bosque en la economía industrial contemporánea. La difusión del procedimiento Hugues y el desarrollo de las nuevas técnicas de destilación permitieron incrementar, extender y regularizar la producción española de resina. La ampliación y diversificación de su empleo industrial, por otra parte, abrió nuevos mercados y consolidó un sector que, en determinadas zonas, podía constituir la única actividad capaz de generar trabajo estable en el sector secundario.

\section{BIBLIOGRAFÍA}

ANÓNIMO (1930-1931): «El problema resinero español», en Montes e Industrias, pp.3-7, 3236, 71-72.

Anuario Estadístico de España, Año IV (1918), Madrid.

Anuario Estadístico de España, Año IX (1924), Madrid.

CALONGE CANO, G. (1987): El complejo ecológico y la organización de la explotación forestal en la Tierra de Pinares segoviana, Segovia.

CAMPO, H. DEL (1888): «Noticias sobre el pino negral o marítimo y la industria resinera en España», en Revista de Montes, Año XII, pp. 193-207, 233-241, 292-301. 
- (1909): Legislación forestal. Colección de Leyes, Decretos y demás disposiciones oficiales dictadas en los años 1833 a 1887, anotadas y concordadas con la Legislación moderna, Madrid.

Catalá y Gavilá, J. B.; DE las Cuevas, y REy, E. (1913): Legislación forestal, Madrid.

Cid RuIz-Zorrilla, A. (1941): La resinación del pinus pinaster en los montes de las llanuras de Castilla, Madrid.

Clement, V. (1999): «El concepto de transición forestal y su interés para la comprensión de los bosques actuales. El ejemplo de la Tierra de Pinares segoviana (s. XI-Xx), en Preactas IX Congreso de Historia Agraria, Bilbao, pp. 413-428.

Elorrieta ArtazA, O. (1945): «La ordenación de montes en España», en Montes, pp. $282-293$.

Estadística general de la producción de los Montes de Utilidad Pública, correspondiente al año forestal... 1900-1901 a 1932-1933.

Ferreras, C., y Arozena, M. E. (1995): Guía física de España 2. Los bosques, Madrid.

Garayo Urruela, J. M.a (1992): «Los montes del País Vasco (1833-1935)», en Agricultura y Sociedad, n. ${ }^{\circ} 65$, pp. 121-174.

GIL, L. (1991): «Consideraciones históricas sobre "pinus pinaster" Aiton en el paisaje vegetal de la península ibérica», en Estudios Geográficos, n. ${ }^{\circ}$ 202, pp. 5-27.

Gómez MendozA, J. (1992): Ciencia y política de los montes españoles (1848-1936), Madrid.

Groome, H. (1985): «El desarrollo de la política forestal en el Estado Español: desde el siglo XIX hasta la Guerra Civil», en Arbor, n. ${ }^{\circ}$ 474, pp. 59-89.

- (1988): El desarrollo de la política forestal en el estado Español: desde la Guerra Civil hasta la actualidad», en Arbor, n. ${ }^{\circ} 505$, pp. 65-110.

HopfNeR, H. (1954): «La evolución de los bosques de Castilla la Vieja en tiempos históricos», en Estudios Geográficos, n. ${ }^{\circ} 56$, pp. 415-430.

Instituto Forestal de Investigaciones y Experiencias. Trabajos de la Sección de Resinas (1931), Madrid.

IRIARTE GOÑI, I. (1996): Bienes comunales y capitalismo agrario en Navarra, 1855-1935, Madrid.

ITURRAlDE, J., y ElORRIETA, O. (1914): Estudio sobre la resinación de los montes españoles en sus aspectos botánico, forestal, industrial y económico, Madrid.

JimÉNEZ BlANCO, J. I. (1991): «Los montes de propiedad pública (1833-1936)», en F. ComíN y P. MARTín ACEÑa (dir.), Historia de la empresa pública en España, Madrid, pp. 241-281.

MADRIGAl COLlazo, A. (1992): «El bosque en el sur de Europa», en VV.AA., El bosque en el espacio rural del sur de Europa, Vitoria, pp. 101-115.

- (1994): Ordenación de montes arbolados, Madrid.

Martínez-Alcubilla, M. (1923, 1924, 1930): Boletín Jurídico-Administrativo. Anuario de legislación y jurisprudencia, Madrid.

Memorias La Unión Resinera Española (1899-1933), Madrid.

NÁJERA Y ANGUlo, F., y RIFÉ LAMPRECHT, M. P. (1951): Resinación con estimulantes químicos. Estudio general y experiencias realizadas en los pinares españoles. I. Ácido clorhídrico, Madrid.

Nicolas, A., y Gandullo, J. M. (1967): Ecología de los pinares españoles I. Pinus Pinaster Ait., Madrid.

SANZ FERNÁNDEZ, J. (1985): «La historia contemporánea de los montes públicos españoles, 1812-1930. Notas y reflexiones (Y)», en R. GARRABOU, J. SANZ (eds.), Historia agraria de la españacontemporánea 2. Expansión y crisis (1850-1900), Barcelona, pp. $193-228$.

- (1986), «La historia contemporánea de los montes públicos españoles, 1812-1930. Notas y reflexiones (II)», en R. GARRABOU, C. BARCIELA, J. I. JiménEz Blanco (eds.), Historia agraria de la España contemporánea 3. El fin de la agricultura tradicional (19001960), Barcelona, pp. 142-170. 
Sumpsi, J. M. (1992): «El sector forestal», Papeles de economía española, n. ${ }^{\circ}$ 50, pp. 123-127.

Tomeo, M. (1939): Las resinas, Barcelona.

URIARTE AYO, R. (1995a): «La industrialización del bosque en la España interior: producción y cambio técnico en la industria resinera (1860-1914)», en Revista de Historia Económica, Año XIII, otoño, pp. 509-551.

- (1995b): «La industria resinera española y el mercado internacional en la segunda mitad del siglo XIX», Siglo XIX. Cuadernos de Historia, Año V, n. ${ }^{\circ} 13$, pp. 65-81.

— (1996): La Unión Resinera Española (1898-1936), Documento de Trabajo, Fundación de Empresa Pública, Madrid.

- (1999), «Expansión y declive de la industria resinera española (1936-1976), en Preactas IX Congreso de Historia Agraria, Bilbao, pp. 771-789.

Woolsey, TH. S. (1921): «Conservative Turpentining by the French. The Methods Pursued in France, Algiers and Corsica», en TH. Gamble (comp.), pp. 175-187.

XÉRIRA, R. (1869): La teoría y la práctica de la resinación, Madrid.

ZAPATA BlANCo, S. (1986): «El alcornoque y el corcho en España, 1850-1935», en R. GARRABOU, C. BARCIELA, J. I. JimÉnez Blanco (eds.), Historia agraria de la España contemporánea 3. El fin de la agricultura tradicional (1900-1960), Barcelona, pp. 230279.

Zimmermann, E. W. (1957): Recursos e industrias del mundo, México.

\section{ABREVIATURAS}

AMA, Archivo del Ministerio de Agricultura.

EGPMUP, Estadísticas Generales de la Producción de los Montes de Utilidad Pública. LURE, La Unión Resinera Española.

MUP, Montes de Utilidad Pública.

RESUMEN: En las décadas que precedieron a la Guerra Civil, la industria resinera española tuvo un intenso desarrollo productivo. Su presencia se extendió en un amplio espacio geográfico, cuyo núcleo fundamental se encontraba en la meseta norte castellana. La calidad y amplitud de las masas de coníferas existentes en numerosas provincias del interior de España, permitieron el desarrollo de una industria transformadora en zonas eminentemente rurales y configuraron un espacio forestal sometido a una intensa explotación y adaptado a los requerimientos de la industria.

Palabras Clave: Historia forestal, Industria resinera, Resina, Bosque, Pinar.

ABSTRACT: In the decades that preceded to the Civil War, the Spanish resin industry had an intense productive development. Their presence extended in a wide geographical space whose fundamental nucleus was situated in the northern Castilian meseta. The quality and extent of the masses of coniferous existent in numerous provinces of the Spanish inland, allowed the development of an industry in eminently rural areas and configured a forest space submited to an intense exploitation and adapted to the requirements of the industry.

KEY WORDS: Forest history, Naval stores, Resin, forest, Pinewood. 